\title{
Karmaşık Vergi Sistemi ve Maliyetleri
}

\author{
Bahadır Sazak Doğan \\ Arş. Gör. Dr., Tokat Gaziosmanpaşa Üniversitesi, İktisadi ve İdari Bilimler Fakültesi, Maliye Bölümü, Tokat, Türkiye \\ bahadirsdogan@gmail.com
}

\begin{tabular}{|c|c|}
\hline Makale Bilgileri & ÖZ \\
\hline \multirow{6}{*}{$\begin{array}{l}\text { Makale Geçmişi } \\
\text { Geliş: } 02.11 .2020 \\
\text { Kabul: } 23.11 .2020 \\
\text { Yayın: } 27.12 .2020 \\
\text { Anahtar Kelimeler: } \\
\text { Vergiler, vergilendirme } \\
\text { ilkeleri, karmaşı vergi } \\
\text { sistemi }\end{array}$} & $\begin{array}{l}\text { Kamusal mal ve hizmet sunumu kendisine özgülenmiş olan devletler, bu sunumu sağlayıp devam } \\
\text { ettirebilmek icin harcamalar yapmakta ve bu harcamaların finansmanı için gelire ihtiyac }\end{array}$ \\
\hline & duymaktadır. Devletlerin finansman kaynakarı içerisinde ise en geniş yeri vergiler tutmaktadır. \\
\hline & Vergiler devletler ile vatandaşlarını karşı karşıya getirmekte ve her iki taraf için de büyük önem arz \\
\hline & etmektedir. Zira, devletler için toplanması gereken en geniş gelir kaynağ iken; vatandaşlar üzerinde \\
\hline & $\begin{array}{l}\text { de bir yük teşkil etmektedir. Diğer bir ifadeyle vergiler, iki tarafa da çeşitli maliyetler } \\
\text { oluşturmaktadır. İlgili çerçevede, bir vergi sistemi oluşturulurken dikkate alınması icap eden vergi } \\
\text { ilkeleri de önem kazanmaktadır. }\end{array}$ \\
\hline & $\begin{array}{l}\text { Bu çalışmada sözkonusu ilkelerden basitlik ilkesi dikkate alınmadan -karmaşı bir yapıda- } \\
\text { oluşturulan vergi sistemlerinin verginin tarafları üzerine yüklediği maliyetler ele alınmıştır. } \\
\text { Karmaşı bir vergi sistemi, verginin toplanması aşamasında idareye maliyetler yüklerken; } \\
\text { mükelleflere ise vergiye uyum gösterme aşamasında maliyetler yüklemektedir. Bu bağlamda, açık, } \\
\text { anlaşılır ve basit bir vergi sisteminin, ilgili maliyetleri azaltmak ve vergi hasılatını arttırmak için } \\
\text { elzem bir özellik olduğu sonucuna ulaşılmıstır. }\end{array}$ \\
\hline
\end{tabular}

\section{Complex Tax System and Its Costs}

\begin{tabular}{ll}
\hline Article Info & ABSTRACT \\
\hline $\begin{array}{l}\text { Article History } \\
\text { Received: } 02.11 .2020\end{array}$ & $\begin{array}{l}\text { States, which are dedicated to present public goods and services, make expenditures in order to } \\
\text { provide and maintain this presentation and need income to finance these expenditures. Taxes take } \\
\text { the largest place in the financing resources of the states. Taxes confront states with its citizens and }\end{array}$ \\
$\begin{array}{l}\text { Accepted: } 23.11 .2020 \\
\text { Published: } 27.12 .2020\end{array}$ & $\begin{array}{l}\text { are of great importance to both sides. Because, while taxes are the largest source of income for states } \\
\text { to collect; they poses a burden on citizens. In other words, taxes cause various costs to both sides. In } \\
\text { the relevant context, tax principles, which must be taken into account when establishing a tax system, } \\
\text { Keywords: }\end{array}$ \\
$\begin{array}{l}\text { Taxes, } \\
\text { Taxation principles, }\end{array}$ \\
$\begin{array}{l}\text { In this study, the costs imposed on the both sides of the taxation by the tax systems which established } \\
\text { in a complex structure without taking into account the principle of simplicity are discussed. While a } \\
\text { complex tax system imposes a cost on the administration at the stage of tax collection; it imposes } \\
\text { costs on taxpayers during the tax compliance phase. In this context, it has been concluded that a clear } \\
\text { and simple tax system is an essential feature to reduce associated costs and increase tax revenue. }\end{array}$
\end{tabular}

Atıf/Citation: Doğan, BS. (2020). Karmaşık Vergi Sistemi ve Maliyetleri, Necmettin Erbakan Üniversitesi Siyasal Bilgiler Fakültesi Dergisi, 2(2), 129-139.

"This article is licensed under a Creative Commons Attribution-NonCommercial 4.0 International License (CC BY-NC 4.0)" 


\section{GİRIŞ}

Toplumsal ihtiyaçları gereği bir arada yaşamaya başlayan insan toplulukları, örgütlü bir üst yapıya ihtiyaç duymuşlardır. Bu ihtiyacın bir tezahürü olarak ortaya çıkmış olan devletlerden ise eğitim, sağlık, güvenlik, savunma, refah ve huzuru sağlamak gibi çeşitli temel hizmetleri sağlaması beklentisi içerisine girmişlerdir. İşte devletler, bu hizmetleri sağlayabilmek için çeşitli harcamalar yapmakta ve bu harcamaları finanse edebilmek için ise çeşitli gelir kaynaklarına ihtiyaç duymaktadır. Bu gelir kaynakları arasında en büyük paya sahip olan ve en önemli olanı ise vergilerdir. Devletin devamlılığ1 için gereksinim duyduğu finansman kaynağ teknik gelişmelerle ilintili olarak nitel ve nicel anlamda değişimler göstermiştir. Aynı zamanda, tarihi süreçte, artan ve çeşitlenen kamu hizmetlerine paralel olarak, devletlerin topladığ 1 vergiler de bir artma sürecine girmiştir.

Devletlerin hükümranlık güçleri çerçevesinde, ekonomik, mali ve sosyal amaçlı kamu giderlerini finanse etmek için, bireylerin mali güçleri oranında, karşılıksız olarak ve belli kurallar dahilinde aldığı, kanuni ve cebri ekonomik değerler olan vergilerin hem vergi idaresi hem de vergi mükellefleri üzerinde önemli etkileri bulunmaktadır. Bu sebeple, vergi sistemleri hazırlanırken, vergileme ilkelerine uyulmalı ve düzgün işleyen bir vergi sistemi oluşturulmasına azami gayret gösterilmelidir. Çünkü devletler, vergilerden elde ettikleri gelirleri en üst düzeye ulaştırmak için vergilerin muhattabı olan mükelleflerin en az düzeyde direnç göstermesini arzu etmekte ve beklemektedir.

Bir vergi sisteminin tasarım, oluşum ve uygulama aşamalarında dikkate alınması gereken vergileme ilkeleri; uzun bir deneyim süreci sonunda ortaya çıkmış ve vergi sisteminin kendisinden beklenen, mali, ekonomik ve sosyal amaçları yerine getirebilmesi için uyulması gereken ilkeler bütünüdür (Devrim, 1996, s. 181). Bir vergi sistemi baştan tasarlanırken ya da gözden geçirilirken, sistemin yukarıda bahsi geçen amaçlara ulaşabilmesi için, kanun koyucular bu vergileme ilkelerini dikkate almak durumundadırlar. Zira vergiler, devletlerin birincil gelir kaynaklarından olması; mükelleflerin ise harcanabilir gelirleri ve servetleri üzerindeki daraltıcı etkisi hasebiyle bu iki tarafı da yakından ilgilendirmektedir.

Bu çalışmada, vergi sisteminin karmaşıklaşmasına yol açan nedenler ve bu karmaşıklığın gerek idareye gerek mükelleflere yüklediği maliyetler klasik vergileme ilkelerinden olan basitlik ilkesi çerçevesinde mercek altına alınmıştır.

\section{VERGILEME İLKELERİ VE BASITLLIK İLKESI}

İşler bir vergi sistemi tasarlamak kamu ekonomisinin temel konularından bir tanesidir. Böyle bir sistem, vergilendirmenin arzu edilen karakteristiklerini barındırıyor olmalıdır. Bu karakteristikler; bireylere adil davranması, bireylerin ekonomik kararlarına en az seviyede müdahale etmesi ve vergi idaresi ve mükelleflere aşırı maliyetler yüklememesidir (Alm, 1996, s.117). Bu bağlamda, etkin ve işler bir vergi sistemi oluşturulmasında dikkate alınması gereken vergileme ilkeleri, literatürde birçok kaynakta ele alınmış konulardan bir tanesidir ve maliye teorisyenleri optimal bir vergi sistemi için bu ilkeleri çoğaltma eğilimindedirler (Gökbunar, 1998, s. 178). İlk olarak, İskoçyalı ekonomist Adam Smith (1776), Ulusların Zenginliği isimli eserinde, verimli bir vergi sistemi oluşturabilmek için, vergilemede adalet, vergilemede açıklık, ödemede uygunluk ve vergi toplamada ekonomiklik olmak üzere dört temel ilke ileri sürmüştür. Adolph Wagner (1958) ise, Smith'in vergileme ilkelerini referans alarak vergileme ilkelerini iktisadi ilkeler, mali ilkeler, vergi idaresi ilkeleri ve adalet ilkeleri olmak üzere dört başlık altında toplamıştır. Basitlik ilkesi, vergi idaresi ilkelerinin alt başlıklarından bir tanesidir. Fritz Neumark (1970) da çalışmasında, işler bir vergi sistemine kılavuz olması gereken dört temel ilke grubu belirlemiştir: bütçesel ve mali ilkeler, sosyo-politik ve etik ilkeler, politik ve ekonomik ilkeler, yasal ve 
teknik ilkeler. Açıklık ilkesi, yasal ve teknik ilkeler ana başlı̆̆ı altında yer almaktadır. Aktarılan önde gelen iktisatçıların çalışmalarında belirttikleri temel ilkelere müteakiben, evrilen ekonomik, mali ve sosyal konjonktür ile beraber bu temel ilkelere eklemeler olmuştur.

Teorisyenlerle birlikte, bazı önemli raporlarda ${ }^{1}$ da vergileme ilkelerine değinilmiştir. Örneğin, 1966 yılında Kanada'da yayımlanan Carter Raporu'na göre de ekonomik ve sosyal hedeflere ulaşmada bir enstrüman olarak kullanılacak vergi sistemi, adalet, yansızlık, şeffaflık ve hesap verebilirlik, kesinlik, basitlik ve esneklik kriterleri kapsamında vücuda getirilmedir. Yine 1975'te Avusturalya' da yayımlanan Asprey Raporu'nda, 1978'de Birleşik Krallık'ta yayımlanan Meade Raporu'nda ve 1982'de İrlanda'da yayımlanan O'Brien Raporu'nda da etkin bir vergi sisteminde uyulması gereken ilkelerden bir tanesi basitlik ilkesidir. Ek olarak, OECD Mali İşler Komitesi'nin 1998 yılında yayımladığı raporda, elektronik ticarette söz konusu olması gereken vergilerin temel ilkelerinden bir tanesinin basitlik ilkesi olmas1 gerektiği vurgulanmaktadır. Benzer şekilde, 2017'de Amerikan Yeminli Mali Müşavirler Enstitüsü (American Institute of Certified Public Accountants/AICPA) tarafindan vergi sistemlerinde reforma giden ülkeleri yönlendirmek için yapılan çalışmada da, iyi bir vergi sisteminin belirli temel ilkeler çerçevesinde oluşturulması gerekliliği belirtilmiştir. Bu ilkeleri eşitlik ve adalet, kesinlik, ödeme kolaylı̆̆ı, etkin vergi idaresi, bilgi güvenliği, basitlik, tarafsızlık, ekonomik büyümeyi destekleyicilik ve verimlilik, şeffaflık ve görünürlük, minimum vergi açığı yaratıcı yapıya sahip olmak, hesap verebilirlik ve etkin devlet geliri sağlayıcı yapıya sahip olmak şeklinde saymak olanaklıdır.

Aktarılan örneklerden anlaşılacağı üzere; vergi sisteminin basit, açık, belirli ve kesin olması, vergi teorisyenlerince üzerinde uzlaşı bulunan bir gerekliliktir. Bu ilkeler kapsamında, ödeme şekli ve yeri, ödeme zamanı ve tutarı açık ve net olmalıdır. Diğer bir ifadeyle, vergi düzenlemeleri, mükelleflerce kolayca anlaşılır ve uygulanabilir bir şekilde vücuda getirilmelidir. Daha açık bir deyişle, bir vergi kanunu; okunabilir, doğru anlaşılır ve pratik olarak uygulanabilir olmalıdır (Sağbaş, 2008, s. 209-210).

Bireylerin devletleri ile mecburi mahiyetteki ilişkilerinin en önemli sebeplerinden birisi vergilerdir. Bu ilişkide bireylerin vergilerini ödeyip/ödememe davranışları arkasındaki saikler farklılık gösterebilmektedir. Takip eden bölümde, bireylerin vergi hususundaki tutumları üzerinde etkisi olan unsurlar aktarılmıştır.

\section{MÜKELLEFLERIN VERGIYE YÖNELIK TUTUMLARINI ETKILEYEN UNSURLAR}

Mükelleflerin vergi konusundaki tutum ve davranışlarını etkileyen unsurları kişisel unsurlar ve kişisel olmayan unsurlar olmak üzere iki başlık altında incelemek olanaklıdır. Kişisel unsurlar (Tuay ve Güvenç, 2007, s.20-32);

- Eğitim Seviyesi

- Gelir Seviyesi

1 Carter Raporu: Kanada Kraliyet Komisyonu tarafından, ekonomik ve sosyal hedeflere ulaşmakta vergi sisteminin kullanımı kapsamında hazırladığı rapordur.

Asprey Raporu: Avustralya Vergilendirme İnceleme Komitesi tarafindan yayımlnana, vergi sistemlerinin sahip olması gereken kriterleri belirtildiği rapordur.

Meade Raporu: Birleşik Krallık’ta yayımlanan, iyi bir vergi yapısının sahip olması gereken karakteristik özellikleri belirten bir rapordur.

O'Brien Raporu: İrlanda'da vergi sisteminin ölçütlerinin belirtildiği vergilendirme komitesi raporudur.

OECD Raporu: Mali İşler Komitesi tarafindan yayımlanan, elektronik ticarette vergilendirmenin çerçeve koşullarının belirtildiği rapordur.

AICPA Raporu: Amerikan Yeminli Mali Müşavirler enstitüsü tarafindan yayımlanan, iyi bir vergi politikasının ilkelerinin belirtildiği rapordur (Alley ve Bentley, 2005, s.586-588). 
- Meslek

- Yaş, Cinsiyet ve Medeni Hal

- Vergi Ahlak1

- Diğer Mükellef Tutumları

- Devlete Bağl1l1k

- Vergilerin Finanse Ettiği Alanlar olarak sıralanabilirler.

Diğer yandan kişisel olmayan unsurları ise:

- Vergilemedeki Adalet

- Vergi Afları

- Vergi Türlerinin Çokluğu

- Vergi Cezaları ve Denetim Sıklığı

- Vergi Oranlar1

- Vergi Sisteminin Karmaşıklığı şeklinde sıralamak mümkündür.

Görüldüğ̈̈ üzere, vergi sisteminin karmaşıklığı, vergi mükellefinin vergiye dair tutumunu etkileyen önemli ajanlardan bir tanesi olabilmektedir.

\section{VERGİ SISTEMINIIN KARMAŞIKLIĞI VE NEDENLERİ}

Vergi sisteminin karmaşık olması, vergi sistemindeki iki taraf -idare ve mükellef- açısından da arzu edilebilir bir durum değildir. Karmaşık vergi sistemi, vergiyi toplayan (hükümet) için yönetsel maliyetleri arttırırken; vergiyi ödeyen (mükellef) için ise uyum maliyetlerinin artmasına neden olacaktır. Aynı zamanda, mükelleflerin vergi sisteminin adaletli olduğuna dair kanılarını zayıflatacaktır (Uğurlu, 2019, s.183).

Vergi ile alakalı düzenlemerin olabildiğince açık, anlaş1ır ve basit bir şekilde tasarlanması, bir yandan idarenin vergi konusundaki keyfi uygulamaların önüne geçerken diğer yandan da mükelleflerin vergiye olan uyumunu arttıracaktır (Çağan, 1982, s. 172). Ancak vergi sistemlerini karmaşıklaştıran pekçok unsurdan bahsetmek olanaklıdır. Örneğin, hükümetlerin vergileri araç olarak kullanmak suretiyle ulaşmaya çalıştıkları hedeflerin artması ve çeşitlenmesi sonucunda vergilerin sayısı da artmakta; bu ise vergi mevzuatını daha karmaşık bir hale getirebilmektedir. Ayrıca vergi sisteminde yer alan ve vergi harcaması olarak tabir edilen indirim, istisna ve muafiyetler de sistemde farklı tarifelerin uygulanmasına ve dolayısı ile sistemin karmaşıklığının artmasına sebebiyet verebilmektedir (Budak vd., 2017, s. 62).

Ayrıca vergi yasaları, kısa vadede vergi konusunda uzmanlığa haiz kişilerce vücuda getirilse de; uzun vadede vücuda getirildikleri dönemdeki siyasal gücün vergi yasaları üzerinde etkileri bulunabilmektedir. Bu etkiler kapsamında vergiler, siyasal gücün toplumun belli bir kesimine ayrıcalık sağlamak üzere kullanabilmektedir; ki bu da vergi sisteminin karmaşıklaşmasına yol açabilmektedir (Karabacak, 2013, s. 20). Ülkelerdeki egemen güç olan iktidarların yapısı da karmaşıklığa etkisi olan unsurlardandır. Zira, gerçekleştirilen irdelemeler, koalisyon hükümetlerince oluşturulan vergi sistemlerinin, tek parti hükümetlerince oluşturulan vergi sistemlerine kıyasla daha karmaşık bir yapıda olduğu işaret etmektedir (Hettich ve Winer, 1999, s. 267-269). 
Vergi sisteminin karmaşıklığı, bireylerin vergiye olan uyum seviyeleri üzerinde negatif etkisi olabilen bir etkendir. Çünkü anlaşılması güç ve karışık olan vergi yasaları mükelleflerin uyumunu güçleştirmektedir. Ek olarak, mükellefler sık değişen ve karmaşık yapıdaki yasalar nedeniyle zaman zaman istemsizce de vergiye uyumsuz olabilmekte, hatalar yapabilmektedirler (Gediz Oral, 2011, s.406). Vergi konusunda yetkin kişilerin dahi takip etmekte zorlandığı vergi yasalarını -sade vatandaşmükelleflerin takip edebilmesi ve uyum gösterebilmesi pek olanaklı olamayabilmektedir (Karabacak, 2013, s. 20). Zira, halihazırda vergi yasalarının teknik içeriği dolayısıyla onu güçlükle kavrayan mükelleflerin yeni bir yasayı kavramaları onlar açısından ızdırap verici olacaktır (Çataloluk, 2008, s. 224). Ayrıca sıkça yapılan söz konusu değişimlerin, mükelleflerin vergi idaresine duydukları güven üzerinde de olumsuz etkiler yaratacaktır (Bahş1, 2019, s. 92). Bir vergi yasasını; yetersiz ifadelerin varlığ1, yasanın özünün karmaşık bir kavramla ilgili olması, birbiriyle çatışan amaçların varlığ ve mükellefle idare arasında çatışan bir vergi kültürünün varlığı gibi faktörler hukuki açıdan karmaşık bir hale getirebilmektedir (Tran-Nam, 2000, s. 243). Diğer bir deyişle, düzenlemelerin içeriğinde yer verilen belirsiz, anlaşılması güç ve teknik ifadelerin karmaşıklığı arttırdığını söylemek mümkündür. $\mathrm{Bu}$ ifadelerin neden olduğu karmaşılıtan ötürü de vergi sisteminden beklenilen sonuca ulaşmak güçleşebilmektedir (Tekbaş, 2010, s. 136).

Vergi sistemindeki karmaşıklığın bir diğer sebebi ise, yürütme organınca tertip edilmekte olan çok sayıdaki kapsamı yoğun düzenlemelerdir. Diğer bir ifadeyle, sistemdeki Bakanlar Kurulu kararlarının, tüzüklerin, yönetmeliklerin, iç genelgelerin, genel yazıların, sirkülerlerin vb. sayıları arttıkça ve içeriği genişledikçe, sistemin karmaşıklık düzeyi de yükselecektir (Karabacak, 2013, s. 22).

Vergi sisteminin karmaşıklı̆̆ını arttıran diğer bir unsur da vergi sisteminin amacından saptırılarak, yanlış amaçlar doğrultusunda kullanılmasıdır (Tran-Nam, 2000). İlaveten, karmaşıklık, vergi yasalarının uzunluklarına ve anlaşılma güçlüklerine, itilaflı konuların çokluğuna, uygulanan vergisel kolaylıkların sayısına ve bürokratik işlem sayılarına göre de artış gösterebilmektedir.

Özetle, bir vergi sisteminin karmaşık olması (Edwards, 2005, s. 3-4):

- Vergini iki tarafı için de yüksek maliyetler doğurmakta,

- Vergi kaçırma ve vergiden kaçınma için firsatlar yaratmakta,

- Vergi yasalarının adil olmadığı algısına neden olmakta,

- Birey ve firmaların karar alma süreçlerini olumsuz etkilemekte,

- Mükelleflerin ve vergi idaresinin hatalar yapmalarına sebebiyet vermekte,

- Kişisel mahremiyetin devletçe ihlalini teşvik etmekte ve

- Vergi sistemine olan uyumu azaltmaktadir.

Karmaşık vergi düzenlemeleri, verginin taraflarının sık sık ve önemli hatalar yapmasına neden olabilmektedir. Ayrıca bu karmaşıklık, mükellefleri, vergi yasalarına uygun davranmamak suretiyle vergi ödememek ya da daha az vergi ödemek şeklindeki yasa dışı bir kavram olarak tanımlanan vergi kaçırmaya ve vergiden doğan yükümlülüklerin yine vergi yasaları çerçevesinde en aza indirilmesi faaliyeti olarak tanımlanan vergiden kaçınmaya yöneltebilecektir (Edizdoğan, 2000). Hangi yol aracılığıyla olursa olsun, vergilerini ödemeyen mükellefler ise devletin vergi gelirlerinde bir erozyona, diğer bir ifadeyle azalmaya sebebiyet vereceklerdir (Stiglitz, 2000).

Karmaşık yapıdaki bir vergi sisteminin, yapılan düzenlemelerle daha basit bir yapıya kavuşturulması sonucunda, mükelleflerin vergiye dair düzenlemeleri kavrama yeteneklerinin artmasına 
(Mumford, 2015, s. 196) müteakiben, vergi gelirleri artacak, uygulama ve denetim kolaylaşacak, vergi kaçırma ve vergiden kaçınma faaliyetleri azalacak, vergi itaati artacak, vergi sistemi ve idaresine olan güven artış gösterecektir (Demirli, 2009, s. 18). Bu bağlamda, vergi sistemlerinin basitleştirilip sadeleştirilmesi büyük önem arz etmektedir. İdeal bir vergi sisteminde bulunması gereken temel özelliklerden bir tanesi olan basitliğe ulaşılabilmesi için iki hayati düzenleme yapılması gerekliliği öne sürülmektedir. Bunlardan ilki anayasada vergi konularının açıkça belirtilmesi; ikincisi ise söz konusu vergilerin düz oranlı olarak düzenlenmesidir (Aktan, 2012, s. 33).

Yukarıda aktarıldığı üzere, siyasi, hukuki, sosyal vb. pekçok unsur vergi sistemlerinin karmaşık bir yapıya bürünmesine sebebiyet verebilmektedir ve açık-anlaşılabilir olmayan, karmaşık yapıdaki vergi sistemlerinin hem mükelleflerin hem de vergi idaresinin katlandıkları maliyetleri arttırdığ gözlemlenmektedir. İlgili çerçevede, izleyen bölümde, mükelleflerin ve vergi idaresinin vergi sistmeinin karmaşık yapısı nedeniyle katlandığı maliyetler aktarılmıştır.

\section{KARMAŞIK VERGİ SISTEMININ MALIYETLERI}

Vergi sisteminin karmaşık olmasının verginin tarafları için farklı etkileri vardır. Karmaşık vergi sistemi, mükellefler üzerinde uyum maliyetleri yaratırken; idare için de çeşitli maliyetlere sebebiyet vermektedir (Slemrod, 1989, s.157).

\section{Uyum Maliyetleri}

Uyum maliyetleri, mükelleflerin vergi yasalarının ve vergi idaresi uygulamalarını gereği gibi yerine getirmek için katlandıkları maliyetlerdir. Uyum maliyetleri, parasal uyum maliyetleri ve parasal olmayan uyum maliyetleri olarak ikiye ayrilabilmektedir. Parasal uyum maliyetleri; muhasebe, kırtasiye, avukat ve telefon masrafları olarak sıralanırken, parasal olmayan uyum maliyetleri; zaman, stres ve endişe olarak sıralanmaktadır. İlgili bağlamda, mükelleflerce katlanılan maliyetleri;

- Vergi mükelleflerinin veya onların yerine vergisel yükümlülüklerini yerine getirmeye çalışan üçüncü kişiler tarafindan yapılan açık ödemeler,

- Vergi mükelleflerinin vergi ile yükümlülüklerine uymak için harcanan zaman maliyeti,

- Vergi mükelleflerinin bir vergi mevzuatı ile uğraşırken yaşadıkları kaygı ve stres gibi psikolojik maliyetler

- Diğer bazı uyum maliyetleri şeklinde toplulaştırmak mümkündür (Yesegat, 2009, s. 20-21).

Mükelleflerin vergi sistemine uyumunu zorlaştıran mali ve ekonomik, hukuki, idari, sosyal ve siyasal nedenler gibi çeşitli nedenler bulunmaktadır. Bu nedenler:

- Mali ve ekonomik nedenler:

- Enflasyon

- Gelir dağılımı bozuklukları

- Vergilemede adaletsizlik

- Hukuki nedenler:

- Vergi kanunlarının basit ve açık olmaması

- Vergi yasalarının sık sık değiştirilmesi

- İstisna ve muafiyetlerin çokluğu

- Vergi cezalarındaki yetersizlik 
- İdari nedenler:

- Vergi dairesinin organik yapısı

- Teknik yapı

- Personel yapis1

- Denetim mekanizmasının etkinsiz olması

- Sosyal nedenler:

- Vergi ahlakı

- Mükellef psikolojisi

- Siyasi nedenler ve baskı grupları kaynaklı nedenler başlıkları altında gruplanabilir (Şaan, 2008, s. 9).

Yukarıda belirtildiği üzere, basit olmayan aksine karmaşık olan bir vergi sistemi hem verginin yönetsel maliyetlerini arttıracak hem de mükellefleri, vergi kaçırma ve vergiden kaçınma faaliyetlerine itecektir. Bundan ötürü, mükelleflerin kayıt dışında kalıp, vergi kaçırma faaliyetlerini azaltmak isteyen kanun koyucular, vergi sisteminin basitliğini sağlamalıdırlar. Ayrıca vergi sisteminin basitleştirilmesi durumunda, mükelleflerin vergi kanunlarının özünü anlayamamaktan ötürü vergiye gösterdiği uyumsuzluğun bahanesi de kalmayacaktır (Üyümez, 2016, s. 89).

Aynı zamanda vergi yasalarının sık sık değişime uğramamasını sağlamak, istisna ve muafiyetleri azaltmak, vergi aflarını azaltmak, etkin denetim ve ceza kurumlarını oluşturmak, mükellefleri vergi ödemeye yönlendirecek diğer uygulamalar olacaktır.

\section{İdarenin Maliyetleri}

Bir vergi sisteminin işleyiş sürecinde idarenin beş faaliyeti yürüttüğünden bahsetmek olanaklıdır. Bunlar; vergi politikasının tasarlanması ve planlanması, vergi kanunlarının hazırlanması ve kabul edilmesi, vergi sisteminin yönetilmesi, vergi yapısına uyum sağlanması ve vergi uyuşmazlıklarının çözüme kavuşturulması faaliyetleridir (Tran-Nam, 1999, s.505). İşte vergi idaresi bu faaliyetlerini yerine getirebilmek için çeşitli maliyetlere katlanmaktadır. Diğer bir deyişle, idarenin maliyetleri, vergi sistemini kurarken, yasaların yürütülmesini sağlarken ve vergileri toplarken sarf ettiği kaynakların maliyetleridir. Ek olarak, vergi idaresi personelinin eğitimi ve yönetimi, mükelleflere ait bilgilerin elde edilip depolanması ile ilgili maliyetlerde idarenin maliyetleri arasındadır (Hettich ve Winer, 1988, s. 706).

Görüldüğü üzere, vergi sistemi hem idareye hem de mükellefe çeşitli maliyetler yükleyen bir sistemdir. Karmaşık bir vergi sisteminin varlığı, hem vergiyi ödeyen taraf olan mükellef tarafından hem de vergiyi toplayan taraf olan vergi idaresi tarafindan katlanılmak durumunda olan maliyetlerin yükselmesine neden olacaktır. Oysaki bu maliyetlerin aşağı çekilmesi hem idare hem de mükellef açısından çok önemlidir. Zira, idare için daha az maliyet, daha çok vergi geliri anlamına gelirken; mükellefler için daha az maliyet daha çok harcanabilir gelir anlamına gelmektedir (Aktan, 2012, s. 52).

\section{SONUÇ}

İnsan toplululuklarının örgütlü bir üst yapıya ihityaç duymaları nihayetinde ortaya çıkmış olan devletletler, vatandaşlarına kamusal mal ve hizmet sunumu gerçekleştirmekte; bu sunumu ve sunumun devamlılığını sağlayabilmek üzere gelire ihtiyaç duymaktadır. Bu bağlamda, devletlerin en baskın gelir 
kaynağı olan vergileri, devletlerle vatandaşlarını karşı karşıya getiren, onları mecburi bir ilişki içerisine sokan unsurlar olarak betimlemek olanaklıdır.

İlgili çerçevede, devletler ile vatandaşları arasındaki vergi ilişkisinin sağlıklı temeller üzerine oturtulması da bir gereklilik olarak kendisini göstermektedir. Bu aşamada, işler vergi sistemlerinin oluşturulmasında dikkat edilmesi gereken ilkeler olan vergileme ilkeleri karşımıza çıkmaktadır. Tarihsel süreçte, her geçen gün artan ve çeşitlenen kamusal mal ve hizmet yelpazesi neticesinde evrilen devlet yapıları ile beraber vergi sistemlerinin yapıları da değişmiş; bu değişimler vergileme ilkelerinde geliştirme ve eklemeleri zaruri kılmıştır.

İşler bir vergi sisteminde olması gereken temel vergileme ilkelerinden biri olan basitlik ilkesi, verginin iki tarafi -vergi alan ve vergi ödeyen- açısından da büyük önem arz etmektedir. Gerek iki tarafın da maliyetlerinin azaltılmasında gerekse de vergi hasılatının çoğaltılmasında basitlik ilkesi önemli ilkelerden birisi olarak ön plana çıkmaktadır. Zira, karmaşık yapıdaki bir vergi sistemi hem idarenin yönetsel maliyetlerini hem de mükelleflerin yüklenmiş olduğu uyum maliyetlerini arttırmaktadır.

Günümüzde vergi sistemlerine yakından bakıldığında, çok sayıda ve çeşitli faktörün vergi sistemlerinin karmaşıklaşmasına hizmet ettiği gözlemlenmektedir. Bu faktörler, siyasi faktörler olabildiği gibi hukuki, sosyal vb. faktörler de olabilmektedir.

Vergi yasalarındaki karmaşıklığın azaltılması ve basitliğin arttırılması, idarenin ve mükelleflerin bu yasaları daha iyi anlayıp, gereklerini daha iyi bir biçimde yerine getirmelerini sağlayacak, maddi/manevi çeşitli saiklerle vergi dışında kalmayı tercih eden mükelleflerin, sistem içerisine alınmasını kolaylaştıracaktır. Dolayısı ile de vergi gelirlerinde bir artış meydana gelecektir.

İlgili çerçevede, vergi sistemindeki karmaşıklığı azaltmak öncelikli hedeflerden bir tanesi olmalıdır. Karmaşıklığı azaltmak için ise; yasaların metinleri sadeleştirilmeli, açık ve basit bir dil kullanılmalı ve ayrıntılara boğulmamalı, mevzuattaki cümleler kısaltılarak anlaşılabilirliği arttırılmalı, muafiyet-indirim-istisna gibi uygulamalar en aza indirilmeli, yasaların sıç̧a değişmesinin önüne geçilmeli, yasalar vergi uzmanlarından destek alınarak mükellef odaklı bir şekilde hazırlanmalıdır.

Son tahlilde, politika yapıcılar vergi sistemini oluştururlarken, vergileme ilkelerini dikkate almalıdırlar. Etkin ve verimli, mükelleflerce de anlaşılan ve kabul edilen bir vergi sistemi hem kamu gelirlerini arttıracak hem de devlet-vatandaş ilişkilerinde olumlu gelişmeleri sağlayacaktır.

\section{KAYNAKÇA}

Alley, C. \& Bentley,D. (2005). A Remodelling of Adam Smith's tax design principles. Australian Tax Forum, 20, 579-624

Aktan, C. C. (2012). İdeal Vergi Sistemi Tasarımı ve Optimal Vergileme. In C. C. Aktan, A. Kesik, \& D. Dileyici (Eds.), "Yeni" Maliye (pp. 23-68). Ankara: T.C. Maliye Bakanlığı Strateji Geliştirme Başkanlığı Yayın No. 2012/420.

Alm, J. (1996). What Is An "Optimal" Tax System? National Tax Journal, 49(1), 117-133.

Bahşı, S. (2019). Vergi Kaçakçıllı̆ının Nedenleri. İzmir YMMO Dergisi, 1(2), 89-95.

Budak, T., James, S., \& Benk, S. (2017). Vergi Sisteminin Basitleştirilmesi: Kavramsal Bir Değerlendirme. In A. Gerçek, \& Ö. Çetinkaya (Eds.), Maliye araştırmaları -1- (pp. 61-84). Bursa: Ekin Basın Yayım Dağıtım. Çağan, N. (1982). Vergilendirme Yetkisi. İstanbul: Kazancı Hukuk Yayınları.

Çataloluk, C. (2008). Vergi Karşısında Mükelleflerin Tutum ve Davranışları. Selçuk Üniversitesi Sosyal Bilimler Enstitüsü Dergisi, 20, 213-228.

Demirli, Y. (2009). Gelişmekte Olan Ülkelerde Vergi Reformları ve Türkiye'de Gelir Üzerinden Alınan Vergiler Açısından Değerlendirme. Doktora Tezi, Hacettepe Üniversitesi, Ankara.

Devrim, F. (1996). Kamu Maliyesine Giriş. İzmir: Anadolu Matbaası.

Edizdoğan, N. (2000). Kaтu Maliyesi. Bursa: Ekin Kitabevi.

Edwards, C. (2005). Options for Tax Reform. Policy Analysis, 536, 1-41. 
Gediz-Oral, B. (2011). Mali Yolsuzlukla Mücadele Stratejileri: Türk Vergi Sistemi. Süleyman Demirel Üniversitesi İktisadi ve İdari Bilimler Fakültesi Dergisi, 16(3), 403-431.

Gökbunar, A. R. (1998). Vergileme İlkeleri ve Küreselleşme. Celal Bayar Üniversitesi İktisadi ve İdari Bilimler Fakültesi Dergisi, 4, 177-201.

Hettich, W., \& Winer, S. L. (1988). Economic and Political Foundations of Tax Structure. The American Economic Review, 78 (4), 701-712.

Hettich, W., \& Winer, S. L. (1999). Democratic Choice and Taxation: A Theoretical and Empirical Analysis. ABD: Cambridge University Press.

Karabacak, Y. (2013). Vergi Karmaşıklığı Modern Vergi Sistemlerinin Kaçınılmaz Sonu Mudur? Mali Çözüm Dergisi, 120, 15-30.

Mumford, A. (2015). Tax Complexity, Tax Salience and Tax Politics. Social \& Legal Studies, 24(2), 185201.

Neumark, F. (1970). Grundsatze gerechter und ökonomisch rationale Steuerpolitik. Tübingen: J.C. B. Mohr (Paul Siebeck)

Sağbaş, İ. (2008). Vergi Teorisi. Ankara: Ece Matbaası.

Smith, A. (1776). The Wealth of Nations. Oxford: Oxford University Press.

Slemrod, J. (1989). Complexity, Compliance Costs, and Tax Evasion. In J. A. Roth \& J. T. Scholz (Eds.), Taxpayer Compliance (pp. 156-181). Pennsylvania: University of Pennsylvania Press.

Stiglitz, J. E. (2000). Economics of The Public Sector. New York: W.W. Norton\&Company.

Şaan, A. (2008). Türkiye'de Vergi Kaçakçılı̆̆ının Önlenmesinde Vergi Denetiminin Etkinliği. Yüksek Lisans Tezi, Trakya Üniversitesi, Edirne.

Tekbaş, A. (2010). Vergi Kanunlarının Tabi Olduğu Anayasal İlkeler. Dokuz Eylül Üniversitesi Hukuk Fakültesi Dergisi, 12, 123-191.

Tran-Nam, B. (1999). Tax Reform, Tax Simplification: Some Conceptual Issues and a Preliminary Assessment. Sydney Law Review, 21(3), 500-522.

Tran-Nam, B. (2000). Tax Reform and Tax Simplicity: A New And 'Simpler' Tax System?. UNSW Law Journal, 23(2), 241-251.

Tuay, E., \& Güvenç, İ. (2007). Türkiye'de Mükelleflerin Vergiye Bakışı. (Yayın No. 51). Ankara: Gelir İdaresi Başkanlığı Mükellef Hizmetleri Daire Başkanlığı.

Uğurlu, H. (2019). Vergilendirmede Basitlik İlkesi Açisindan Türk Vergi Sisteminin Değerlendirilmesi. The Journal of International Scientific Researches, 4(2), 178-194.

Üyümez, M. E. (2016). Vergi Mevzuatının Karmaşıklığı ve Uzlaşma Yöntemi Bağlamında Vergi Uyumunun Değerlendirilmesi. Ekonomi Bilimleri Dergisi, 8(1), 75-92.

Wagner, A. (1958). Three Extracts on Public Finance. In R. A. Musgrave, \& A. T. Peacock (Eds.), Classics in the Theory of Public Finance (pp. 1-15). United Kingdom: Palgrave Macmillan.

Yesegat, W. A. (2009). Value Added Tax in Ethiopia: A Study Of Operating Costs and Compliance. PhD Thesis, University of New South Wales, Sydney. 


\section{EXTENDED ABSTRACT}

Communities, who started to live together due to their social needs, needed an organized managerial institution. The states that emerged as a result of this need were expected to provide various basic services such as education, health, security, defence, welfare and peace. Governments make various expenditures so as to provide these services, and they need various sources of income to finance these expenditures. Taxes, which are the most important source of income, have the largest share. In this context, taxes, as a source of financing needed by the state for its continuity, have undergone qualitative and quantitative changes throughout history in relation to economic, technological and technical developments. At the same time, in the historical process, in parallel with the increasing and diversifying public services, the taxes collected by the states are started to show an increasing trend.

Taxes, which are legal and compulsory economic values, are taken from individuals unrequitedly and in the scope of certain rules within the framework of the sovereignty power of the states, in order to finance public expenditures for economic, financial and social purposes, have significant effects on both the tax administration and taxpayers. For this reason, while preparing tax systems, taxation principles should be followed and maximum effort should be made to establish a properly functioning tax system. Because in order to maximize their income from taxes, states desire and expect the least level of resistance from taxpayers (Devrim, 1996, p.181). When designing or reviewing a tax system, legislators have to take these taxation principles into account in order to achieve the above-mentioned objectives. Taxes have a great importance for the two sides of taxation. Because, on one hand, taxes are one of the primary sources of income for states, on the other hand, due to its narrowing effect on the disposable income and wealth of taxpayers.

In this study, the reasons that lead to complexity of tax systems and the costs that this complexity imposes on both the administration and the taxpayers are examined within the framework of the principle of simplicity, which is one of the classical taxation principles.

\section{TAXATION PRINCIPLES AND SIMPLICITY PRINCIPLE}

Designing an effective tax system is one of the fundamental issues of the public economy. Such a system should have the desirable characteristics of taxation. These characteristics; fair treatment of individuals, minimal intervention in economic decisions of individuals, and not imposing excessive costs on tax administration and taxpayers (Alm, 1996, p.117). In this context, taxation principles, which should be taken into account in establishing an effective and functional tax system, are one of the topics analysed in many sources in the literature, and public finance theorists tend to diversify these principles for an optimal tax system (Gökbunar, 1998, p.178). First, the Scottish economist Adam Smith (1776), in his The Wealth of Nations, put forward four basic principles in order to create an efficient tax system: fairness in taxation, clarity in taxation, convenience in payment and economy in tax collection. Adolph Wagner (1958), on the other hand, based on the taxation principles of Smith, gathered taxation principles under four titles: economic principles, financial principles, tax administration principles and principles of justice. The principle of simplicity is one of the subtitles of tax administration principles. Fritz Neumark (1970) also identified four basic groups of principles that should guide a working tax system: budgetary and financial principles, socio-political and ethical principles, political and economic principles, legal and technical principles. The principle of clarity is included under the main heading of legal and technical principles. Following the basic principles stated by the pioneering economists in their studies, there have been additions to these basic principles with the evolving economic, financial and social conjuncture.

\section{COMPLEXITY OF TAX SYSTEMS AND THE REASONS OF THE COMPLEXITY}

The complexity of the tax system is not desirable for the two sides in the tax system - the administration and the taxpayer. While the complex tax system increases administrative costs for the tax collector (government); it causes an increase in compliance costs for the taxpayer. It also weakens taxpayers' beliefs that the tax system is fair.

It is possible to talk about many factors that complicate tax systems. For example, as a result of the increase and diversification of the targets that governments are trying to achieve through taxes as a tool, the number of taxes also increases; this can make tax legislation more complex. In addition, deductions, exceptions and 
exemptions, which are included in the tax system and defined as tax expenditures, can also cause the application of different tariffs in the system and thus increase the complexity of the system (Budak et al., 2017, p. 62).

Political power in the country can use taxes to privilege a certain segment of the society; which in turn can cause the tax system to become more complex (Karabacak, 2013, p. 20). The structure of governments in countries is also one of the factors that have an effect on complexity. Because, the studies carried out indicate that the tax systems established by coalition governments are more complex compared to the tax systems established by oneparty governments (Hettich ve Winer, 1999, s. 267-269).

Tax laws that change frequently, are laced with technical wording, or contain inadequate wording are also other factors that increase complexity of tax systems (Gediz Oral, 2011, p.406). Another reason for the complexity in the tax systems is the large number of intensive regulations being arranged by the executive bodies (Karabacak, 2013, p. 22). Diversion of the tax system from its purpose and misuse of it will also increase complexity (TranNam, 2000).

\section{THE COSTS OF A COMPLEX TAX SYSTEM}

The complexity of the tax system has different implications for the two sides of the tax systems. While the complex tax system creates compliance costs on taxpayers; it also causes various costs for the administration (Slemrod, 1989, p.157).

Regarding taxpayers, compliance costs are the costs that taxpayers bear to properly comply with tax laws and tax administration practices. Compliance costs can be divided into two titles: monetary compliance costs and non-monetary compliance costs. Monetary compliance costs are accounting, stationery, lawyer and telephone expenses, while non-monetary compliance costs are time, stress and anxiety (Yesegat, 2009, p. 20-21). Regarding administration, the tax administration incurs various costs in order to fulfill its tax-related activities. In other words, the administration costs are the costs of the resources it consumes when setting up the tax system, ensuring the enforcement of laws and collecting taxes (Hettich and Winer, 1988, p. 706).

\section{CONCLUSION}

The principle of simplicity, which is one of the basic taxation principles to be taken into account in an efficient tax system, has great importance for both sides of the taxation, taxpayers and administration. In order to reduce the costs of the taxpayers-administration and increase tax revenues, the principle of simplicity is one of the most important principles.

When we look closely at tax systems today, it is observed that many and various factors serve to complicate tax systems. These factors can be political factors as well as legal, social, etc.

Reducing the complexity and increasing simplicity in tax laws will enable the administration and taxpayers to better understand these laws and fulfill their requirements in a better way and will facilitate the inclusion of taxpayers who prefer to stay out of taxation for various reasons.

Within the relevant framework, reducing the complexity in the tax system should be one of the priority targets of the governments. To do so; the texts of the laws should be simplified, a clear and simple language should be used and not overwhelmed with details, the understandability should be increased by shortening the sentences in the legislation, practices such as exemption-discount-exception should be minimized, frequent changes should be prevented, laws should be prepared in a taxpayer-oriented manner with the support of tax experts. In the final analysis, policy makers should take into account taxation principles when setting up the tax system. An effective and efficient tax system, which is understood and accepted by taxpayers, will both increase public revenues and provide positive developments in state-citizen relations. 